\title{
A Theory of Modern Economic Growth toward Sharing Society
}

\author{
Masayuki Matsui1,2 \\ ${ }^{1}$ The University of Electro-Communications, Tokyo, Japan \\ ${ }^{2}$ Kanagawa University, Yokohama, Japan \\ Email: mmatsui55@nifty.com
}

How to cite this paper: Matsui, M. (2018) A Theory of Modern Economic Growth toward Sharing Society. Theoretical Economics Letters, 8, 675-684.

https://doi.org/10.4236/tel.2018.84045

Received: January 8, 2018

Accepted: March 4, 2018

Published: March 7, 2018

Copyright (c) 2018 by author and Scientific Research Publishing Inc. This work is licensed under the Creative Commons Attribution International License (CC BY 4.0).

http://creativecommons.org/licenses/by/4.0/

\section{cc) (†) Open Access}

\begin{abstract}
Since Industrial Revolution and the division of labor, the wealth of nations is more and more increasing. Although the smaller division of labor is better in GDP, but mass production with larger lot (quantity) is better since Fordism and the division of quantity (lot-size $Q, 0<Q<\infty$ ) is well-known to be worse in manufacturing, for the sake of the larger set-up with penalty. This paper presents the progressive discipline for the contradiction on modern economic growth in the lot-sizing scheme. The theory would govern over from mass-production (larger $Q$ ), mid-lot (EOQ) and disparities (smaller $Q$ ), toward next to sharing equilibrium $(0<Q<1)$. Especially, the Nash's condition for the case of $Q<1$ could be obtained by the duality of flow line vs. job shop. This theoretical review would give the further wealthy development to the gap-wider society of artifacts in the future, and point out that the shared society too could be balanced on the base of the harmonic mean under Industrial-financial capitalism.
\end{abstract}

\section{Keywords}

Economic Growth, Lot-Sizing Scheme, Matsui's Equation, Sharing Economy, Nash's Equilibrium

\section{Introduction}

Since 18-century, the modern economic growth in industry was seen and found first in the European countries by S. Kuznets [1] [2]. On the study, he presented the concept of modern economic growth, and often points out the importance of technology advancement. We would here focus on the shared society in the forthcoming years since Industrial Revolution.

By Industrial Revolution and the division of labor, the wealth of nations is 
more and more increasing [3] and its speed is faster. For GDP, the smaller division is better, but, for mass-production [4], the larger lot (quantity) is well-known to be better since Fordism. Together with the smaller division of labor and larger lot in manufacturing, both were practically effective to the increase of wealth in advanced nations [3].

However, it is remarked that the modern economic growth is now progressive under the smaller lot-size $(0<Q<\infty)$. Generally, the smaller lot-size accompanies with the negative effect of the larger set-up costs under EOQ (Economic order quantity) [5]. Thus, we face on the contradiction (trade-off gap) that the division of lot is inefficient or not at the era of shared economy in $Q<1$ with little reference.

This paper presents a theory on modern economic growth from Mass production (larger $Q$ ), Middle class (EOQ) and Gap-wider stage (smaller $Q$ ), toward Sharing stage $(0<Q<1)$. Because, the recent economic society promotes the smaller lot-size by the more speed of demand-to-supply, but the wealth of nations is more and more increasing [3]. Our theory would give the shared-balancing principle of balancing vs. sharing trade-off in autonomous economy under manufacturing logics.

Especially, it is noted that the shared equilibrium of Nash's type becomes the stability solution with the duality of flowline vs. job shop in the gap-wider stage of wealth [6] [7] [8]. From our theory, the next strategy for forthcoming world could be developed from the gap-wider toward win-win (trade-off) balancing society under sharing economy on the base of harmonic mean (balancing in rates).

\section{Preliminary Introduction}

\subsection{Basics for Lot-Sizing vs. Value Problem}

In the world of global management, the division and span of control would be important. Since the Industrial Revolution and the division of labor, the problem and principle in the manufacturing are discovered in the beginning of 20 century, and developing at the scientific and economic theory [4].

Generally, the production cost of lot-size $(Q), T(Q)$, is given by the sum of set-up, $Z(Q)$, and holding, $L(Q)$, costs as follows:

$$
T(Q)=Z(Q)+L(Q), \quad 0<Q<\infty .
$$

The optimization of the total costs (2.1) is easily obtained, and the solution is called the economic order quantity (EOQ) [8].

Then, let us define the objective: $T(Q) / 2$ by $U(Q)$. From the Equation (2.1) and classical inequality, the following relation are then well-known:

$$
u(\theta)=\{Z(Q)+L(Q)\} / 2 \geq \sqrt{Z(Q) L(Q)}=\sqrt{W(Q)},
$$

by using Matsui's equation: $W=Z L$, too.

If $Z(Q)=L(Q)$, the quantity $Q^{*}$ is become the EOQ formula under some 
demand $(D)$, and the optimal cost is then given by $2 \mathrm{U}\left(Q^{*}\right)$ at equality: $Z=L(=W)$. The outline of the economic quantity, $Q^{*}$, and the relations (2.2) are showed for the larger value (wealth) instead of costs, seen at Figure 1. For Figure 1, it is noted that the $Z$ and $L$ are regarded as the income (revenue) and number of peoples (here, fixed) in the system.

This paper aims the balancing issues at the maximization of total value (wealth) with respect to $Q$ by the objective skewness as follows:

objective skewness:

$$
\begin{aligned}
& \sqrt{E R(\text { income }, Z) \times L T(\text { pepoles }, L)} \\
& -\{E R(\text { income }, Z)+L T(\text { peoples, } L)\} / 2 \rightarrow \operatorname{Max}(Q),
\end{aligned}
$$

where $E R$ and $L T$ means the revenue (economics) and lead time (reliability), respectively.

Especially when $E R$ is equal to $L T$, the system would attain the marginal value, and its value becomes maximal at profit. This principle could be guessed by the findings in pair-map method [9].

\subsection{Flow System and Optimality of OE Type}

For the class of multiple item, the ordered-entry (OE) type of flow-line system is here introduced, and is showed in Figure 2 [9]. The flow-line system of OE type consists of the customers (input) with income $(Z)$ and arrival rate $(\lambda)$, and the line with the processing stations of $n(>1)$ and the respective processing times, $m_{i} \quad\left(0<m_{i}<1\right), \quad i=1, \cdots, n$.

Generally, the cycle time $(Z)$ is given by the sum of the mean processing time

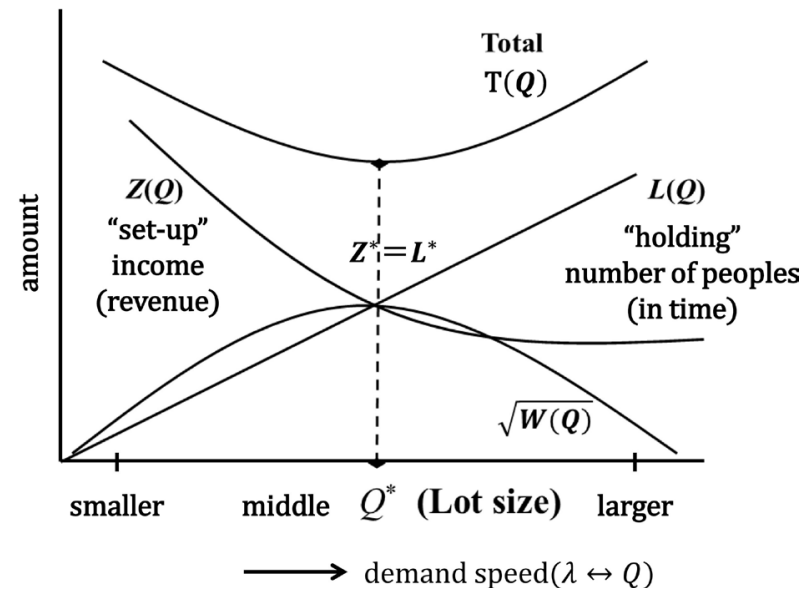

Figure 1. Principal graph for EOQ Lotsizing vs. value problem.

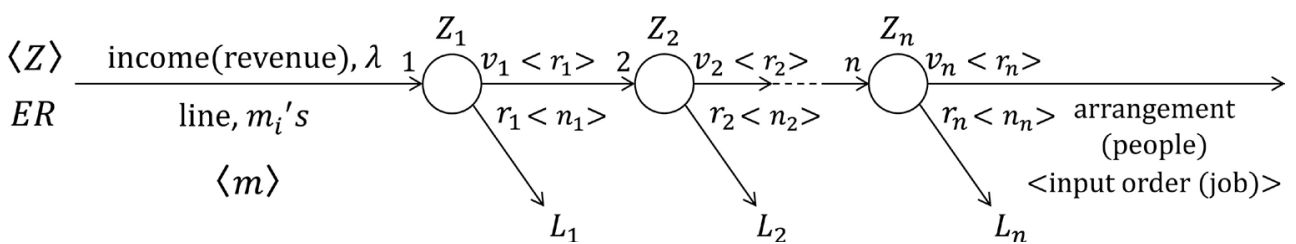

Figure 2. Correnspondence (duality) of flow line $(\theta \mathrm{E})$ vs. job shop $<\mathrm{FS}>$. 
$(m)$ and delay-time $(D)[10]$. If the system has the lost units (overflows), the cycle time, $Z$, is then become $Z=d(=1 / \lambda)$ in the queueing theory with no loss (d) [9]. That is, the cycle time, $Z(d)$, is written as follows:

$$
Z ; d=m+D, d>0
$$

where $d$ is called the mean inter-arrival (namely, inter-departure) time.

Also, the input of arrivals is assumed to have the income, $E R$, and the $E R$ is given by the sum of mean operating cost (expense), $E C$, and benefit, $E N$. Then, the cycle time, $Z$, is as follows:

$$
Z ; E R=E C+E N,
$$

similar to the Equation (2.4).

From Matsui's queueing theory [10], the probability of loss, $B$, is defined by $B=m / Z$, and, from the equation (2.5), another definition is given by

$$
\begin{array}{ll}
B=E C / E R, & 0<B<1 \\
P=E N / E R, & 0<P<1
\end{array}
$$

where $P+B=1$.

For the flowline system of OE type, the production rate $(r)$ is defined by $r=1 / Z$, and is then formulated as follows [7]:

$$
r=\lambda\left\{1-\prod B_{i}(d, c)\right\} \rightarrow \underset{d}{\max \min }
$$

where the vector $c$ is the some variable of buffer effect as $\boldsymbol{c}=\left(c^{1}, c^{2}, \cdots, c^{i}, \cdots, c^{n}\right)$, in which $i$ means the time-range of look-ahead type (time buffer) on the flow line [11].

Then, the optimality condition for the Equation (2.7) is obtained as the equilibrium solution:

$$
\left(d^{*}, c^{*}\right) \text { such that } B_{1}=B_{2}=\cdots=B_{n},
$$

in the balancing of rates (See Appendix).

For the optimal vector, $c$, the monotonicity:

$$
c^{1}, c^{2}, \cdots, c^{i}, \cdots, c^{n}, 0<c^{i}<\infty
$$

is also seen, and satisfies the following relation:

$$
\lambda c^{i}=\lambda_{i+1} c^{i+1}, i=1,2, \cdots, n-1 .
$$

\section{Multi-Item Case of Lot-Size $Q(>1)$}

\subsection{Nash's Equilibrium in Middle Society}

For the engine of higher growth, it is well-known that the mass production has results in the larger GDP since Ford system. This engine is the movement of larger lot-size with $Q \rightarrow \infty$, the modern economic growth is obtained in many developing countries, beginning at the advanced nations.

Now, let us consider the quantity, $Q$, as the input size. That is, the demand speed $(\lambda)$ is regarded as $\lambda=Q$. For multiple items (classes), the lot-sizing issues could be classified as the three stages of economic growth by the larger 
$(Q \rightarrow \infty)$, middle (EOQ), and smaller $(Q \rightarrow 1)$.

Then, the following proposition is given:

Proposition 1. For $1<Q<\infty$, the middle society with EOQ is called the Nash's equilibrium.

$$
\begin{aligned}
& \text { line lot ikko-nagashi } \\
& \text { [mass production } \left.]_{\leq}[\text {middle class }]_{\leq} \text {[gap-wider }\right] \\
& Q \rightarrow \infty \quad \text { EOQ } \quad Q \rightarrow 1 \\
& (Z>L) \quad(Z=L) \quad(Z<L)
\end{aligned}
$$

By the Proposition 1, the top of country rich could be seen at the EOQ age. Following the lot-size, $Q$, toward $Q \rightarrow 1$, the degree of demand-to-supply speed becomes promoted and visualized. At the smaller lot-size $(Q \rightarrow 1)$, the squeal of flow line becomes larger, and grows the gap-wider society of wealth.

At this stage, the present society might not be possible to catch up the global demand speed, and be being retarded to maintain the autonomous self-balancing by invisible hand. By queueing theory, it is well-known that, when the traffic intensity, $\rho(=m / d)$, is approaching to $Q \rightarrow 1$, the state of system could be become unstable.

\subsection{Short Proof for Proposition 1}

For the case of twin item, Proposition 1 could be returned to the following problem of inequality:

Formulation 1:

$$
\left(\frac{Z_{1} L_{1}+Z_{2} L_{2}}{2}\right)_{Z>L} \leq \stackrel{{ }^{\ni}\{Z L\}}{(Z=L)} \geq\left(\frac{Z_{1} L_{1}+Z_{2} L_{2}}{2}\right)_{Z<L} .
$$

where the pair $(Z, L)$ is an equilibrium solution.

Short proof: The proof is divided by the following two cases:

i) $Z \neq L\left(Z_{1} L_{1} \neq Z_{2} L_{2}\right)$ case

$$
\begin{aligned}
& \left\{\left(Z_{1} L_{1}+Z_{2} L_{2}\right) / 2\right\}^{2}-\left\{\sqrt{\left(Z_{1} L_{1}\right)\left(Z_{2} L_{2}\right)}\right\}^{2} \\
& \Rightarrow\left(Z_{1} L_{1}\right)^{2}+\left(Z_{2} L_{2}\right)^{2}-2\left(Z_{1} L_{1}\right)\left(Z_{2} L_{2}\right) \\
& \quad=\left\{\left(Z_{1} L_{1}\right)^{2}-\left(Z_{2} L_{2}\right)^{2}\right\}^{2} \geq 0 .
\end{aligned}
$$

Also,

$$
(Z L)^{2}-\left(Z_{1} L_{1}\right)\left(Z_{2} L_{2}\right) \geq 0 \text {. }
$$

when

$$
Z L>Z_{i} L_{i}\left(Z_{i} \neq L_{i}\right) .
$$

ii) $Z=L\left(Z_{i}<L_{i}\right.$ or $\left.Z_{i}>L_{i}\right)$ case

$$
\begin{aligned}
& Z^{2}\left(=L^{2}\right)-\left(Z_{1} L_{1}+Z_{2} L_{2}\right) / 2 \\
& =\left(Z^{2}+L^{2}\right) / 2-\left(Z_{1} L_{1}+Z_{2} L_{2}\right) / 2 \\
& \geq \frac{1}{2}\left\{\left(Z^{2}+L^{2}\right)-2 Z L\right\}=(Z-L)^{2} / 2 \geq 0,
\end{aligned}
$$


where $Z L>Z_{i} L_{i}$ when $Z=L$.

Thus, the cases of $Z \neq L$ and $Z=L$ complete the proof (3.2).

\section{Theory of Shared-Balancing for $Q<1$}

\subsection{Multi-Item Case of Lot-Size: $Q<1$}

When the lot-size, $Q, Q<1$, the flow line of $\mathrm{OE}$ type is the useful scheme where the income could be regarded as the input to the system. Then, it is noted that this problem could be equivalent to the job shop scheduling problem of sequencing type with LPT (latest processing time) rule [6], if the number of stations in flow line is corresponded to the number of jobs in job shop.

Now, the Pareto-like graph of income (Figure 3) could be considered under the sequencing problem of $n / 1 / \bar{F}$ (mean flow time) type (Table 1 [6]). Similar to Table 1, the Pareto-like graph (Figure 4) is considered under the sequencing problem of $n / 2 / F_{\max }$ (maximum flow time) type (Table 2 [12]).

Then, the following proposition is given:

Proposition 2. The solution of shared-balancing under $Q<1$ is a kind of

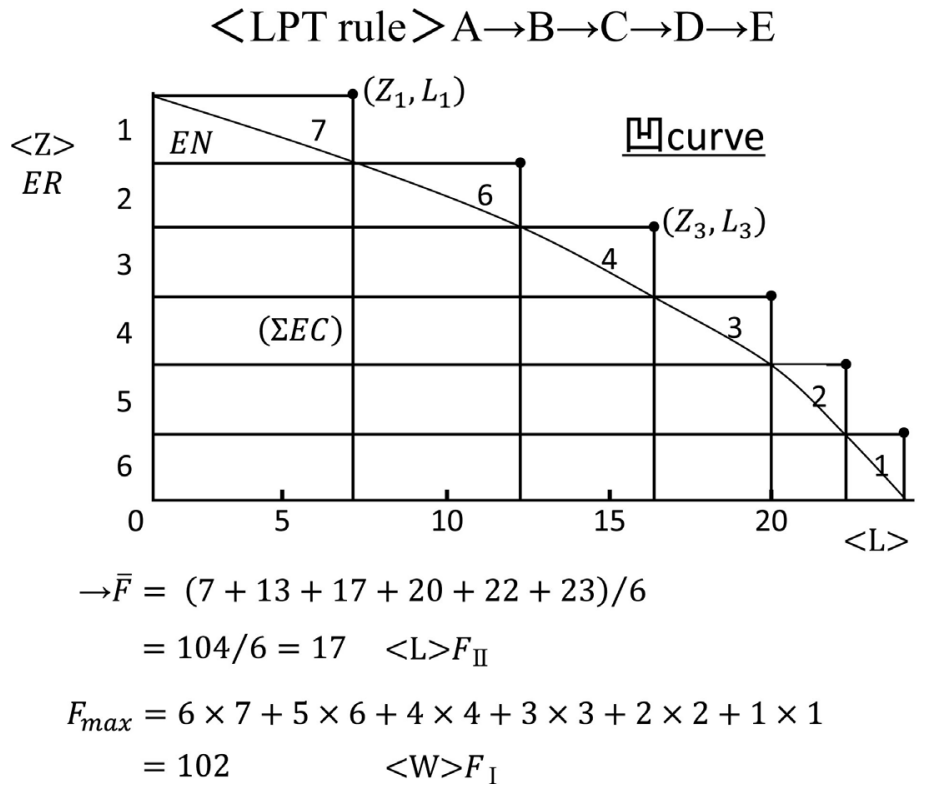

Figure 3. Paret-like graph: Solvable case of $n / 1 / \bar{F}$ type by LPT rule.

Table 1. Sequencing problem: $n / 1 / \bar{F}$ type [5] (case of $E R_{i}\left(Z_{i}\right) \leq x_{i}, i=\mathrm{A} \sim \mathrm{F}$ ).

\begin{tabular}{cc}
\hline class $(i)$ & processing time $\left(x_{i}\right)$ \\
\hline A & 7 \\
B & 6 \\
C & 4 \\
D & 3 \\
E & 2 \\
F & 1 \\
\hline
\end{tabular}


$<$ LPT rule $>5 \rightarrow 3 \rightarrow 4 \rightarrow 1 \rightarrow 2$

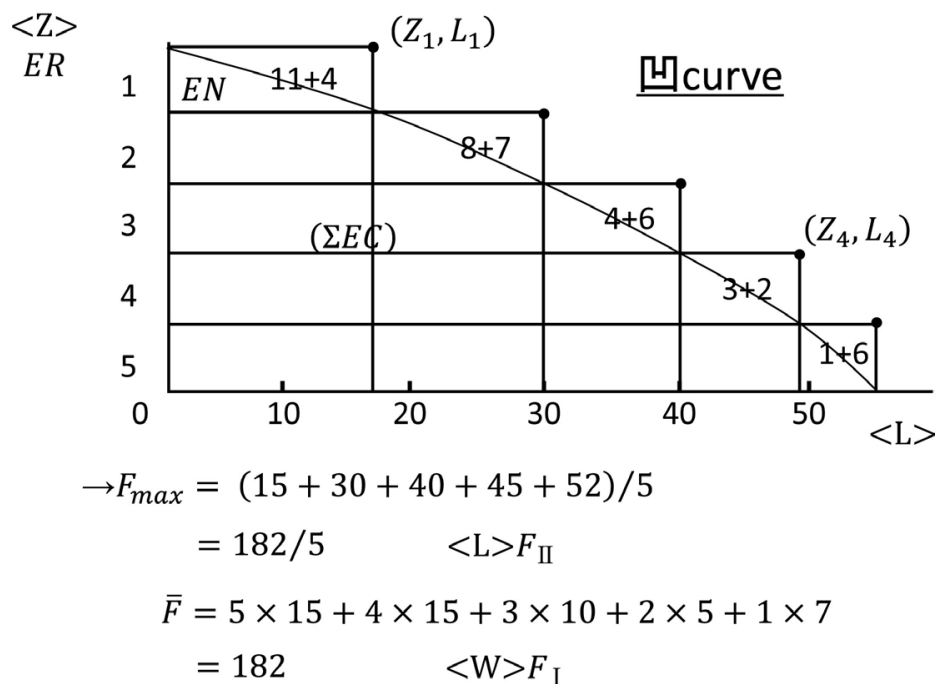

Figure 4. Paret-like graph: Solvable case of $n / 2 / \bar{F}$ type by Johnson rule.

Table 2. Sequencing problem: $n / 1 / \bar{F}$ type [5] (case of $E R_{i}\left(Z_{i}\right) \leq x_{i}, i=\mathrm{A} \sim \mathrm{F}$ ).

\begin{tabular}{ccc}
\hline & \multicolumn{3}{c}{ processing time $(i)$} \\
\cline { 2 - 3 } $\operatorname{class}(i)$ & line $M_{1}\left(x_{1 i}\right)$ & line $M_{2}\left(x_{2 i}\right)$ \\
\hline 1 & 3 & 2 \\
2 & 1 & 6 \\
3 & 8 & 7 \\
4 & 4 & 6 \\
5 & 11 & 4 \\
\hline
\end{tabular}

Nash's equilibrium $(d, c)$ and satisfies the condition: $B_{1}=B_{2}=\cdots=B_{n}$. In the objective (2.6), when $\lambda \rightarrow E R$, the following formulation is obtained:

Formulation 2. The equilibrium problem of shared-balancing under $Q<1$ is formulated as follows:

$$
\begin{aligned}
& r=E R\left\{1-\prod B_{i}(d, c)\right\} \rightarrow \begin{array}{c}
\max \min \\
E R(d) c
\end{array} \\
& \text { subject to }: W\left(F_{\mathrm{I}}\right)=L\left(F_{\mathrm{II}}\right) \times Z(E R) .
\end{aligned}
$$

In Formulation 2, the constraints (4.2) means the condition of Matsui's equation-type, and is related to the equivalence of sharing aspects (set of cells) under vertical vs. horizontal balancing. This is the condition of shared-balancing.

When $\lambda_{1} \rightarrow E R_{1}$, the optimal (equilibrium) condition (4.1) is as follows:

$$
E R_{1} \times c^{1}=E R_{2} \times c^{2}=\cdots=E R_{n} \times c^{n},
$$

where there might be set to $c^{1} \rightarrow E R_{1}, c^{2} \rightarrow E R_{1}+E R_{2}, \cdots$, $c^{n} \rightarrow E R_{1}+E R_{2}+\cdots+E R_{n}$.

Therefore, from the Equation (4.3), the sequences $\left\{E R_{i}\right\}$ and $\left\{c^{i}\right\}$ could be 
obtained equivalently as follows:

$$
E R_{i}=\left(c^{1} / c^{i}\right) E R \text { or } c^{i}=\left(E R_{1} / E R_{i}\right) c^{1}, i=1,2, \cdots, n .
$$

\subsection{Verification of Lot-Size Formulation}

The formulation of sequencing problems, Table 1 and Table 2, gave the Pareto-like graph of the income, $E R(Z)$, in Figure 3 and Figure 4, respectively. The former is called the problem of Johnson rule, and the latter is done the problem of Bowl phenomenon. However, the maximum in Pareto-like graph is not the SPT rule or Bowl phenomenon, but the LPT rule.

That is, the arrangement with LPT rule is better in Figure 3 and Figure 4, and the resulting concave curve shows the gap-wider skew of wealth in Pareto analysis. Furthermore, the Figure 3 and Figure 4 show the mechanism of sharing scheme as follows:

$$
\operatorname{Vertical}\left(E R_{1}\right) \rightarrow \operatorname{Horizontal}\left(E C_{1} \rightarrow E R_{2}\right) \rightarrow \operatorname{Vertical}\left(E R_{2}\right) \rightarrow \cdots
$$

where the Equation (4.5) means the chain of sharing.

Thus, the constraints of Table 1 and Table 2 are outlined as follows:

$$
\left(\begin{array}{c}
\text { "sharing" } \\
\text { vertiacl sum } \\
W\left(F_{\mathrm{I}}\right)
\end{array}\right) \stackrel{\text { equivalent to }}{\longleftrightarrow}\left(\begin{array}{c}
\text { "balancing" } \\
\text { horizontal sum } \\
Z(n) \times L\left(F_{\text {II }}\right)
\end{array}\right)
$$

under the concave curve in Figure 3 and Figure 4.

On the other hand, the objective (4.1) becomes then 1, because the processing time $(x)$ is $x>E R$, the probability of processing, $P$, is $P=1$, and that of loss, $B$, $B=0$, in no overflow case. That is, this optimal condition shows the synchronization of flow time, and then, the production rat, $r, r \rightarrow E R$ in the objective (4.1).

\section{Conclusions and Remarks}

The modern society faces the skewness of autonomous economic balancing by the more speed of demand-to-supply in global world. This problem is here regarded as that of smaller lot-size, $Q \rightarrow 0$, and is treated by Matsui's equation and classical inequality at the lot-sizing class of multiple items in manufacturing.

This theory relates to the artifacts of economic body, and results in the advance of factory science in the multi-body with heterogeneity [13]. From the section 4, the theory could give the framework and design principle in the forthcoming society on the base of harmonic mean (balancing in rates). Probably, this finding could explore a deep and valuable meaning or indication on un-equality vs. democracy toward the financial capitalism in the coming future.

The furthermore problems would be the generalization of short proof $(n=2)$ and its theory on economic ethics, although this former thing could be easily derived from the generality of classical inequality in mean. Also, the advanced theory on the closed OE system would be hoped in not only the coming recycle 
world, but also Adam-like invisible balancing at the shared society under a closed earth.

\section{References}

[1] Simon, K. (1966) Modern Economic Growth: Rate, Structure, and Speed. Yale University Press, New York.

[2] Simon, K. (1973) Modern Economic Growth: Findings and Reflections. American Economic Review, 63, 247-258.

[3] Smith, A. (1776) The Wealth of Nations. Encyclopedia Britanika, Chicago (1952).

[4] Wild, R. (1972) Mass-Production Management-The Design and Operation of Production Flow-Line System. Wiley, London.

[5] Hardly, G. and Whitin, T.M. (1963) Analysis of Inventory Systems. Prentice-Hall, London.

[6] Conway, R.W., Maxwell, W.L. and Miller, L.W. (1967) Theory of Scheduling. Addison-Wesley Co., Boston, MA.

[7] Matsui, M. (2011) Conveyor-Like Network and Balancing. In: Savarese, A.B., Ed., Manufacturing Engineering, Ch.3, NOVA, New York, 65-87.

[8] Matsui. M. (2016) Fundamentals and Principles of Artifacts Science: 3M\&I-Body System, Springer Briefs in Business, Springer, Singapore.

https://doi.org/10.1007/978-981-10-0473-5

[9] Matsui, M. (2014) Manufacturing and Service Enterprise with Risks II: The Physics and Economics of Management. International Series in OR\&MS, No. 202, Springer, Tokyo. https://doi.org/10.1007/978-4-431-54619-1

[10] Matsui, M. (2009) Manufacturing and Service Enterprise with Risks: A Stochastic Management Approach. International Series in OR\&MS, No. 125, Springer, Tokyo. https://doi.org/10.1007/978-0-387-84804-4

[11] Matsui, M. (2005) CSPS Model: Look-Ahead Controls and Physics. International Journal of Production Research, 43, 2001-2025. https://doi.org/10.1080/00207540412331331416

[12] Hitomi, K. (1996) Manufacturing Systems Engineering. 2nd Edition, Taylor \& Francis, London.

[13] Matsui, M. (2005) Management of Manufacturing Enterprise-Profit Maximization and Factory Science. Kyoritsu Shuppan, Tokyo. (In Japanese) 


\section{Appendix}

This appendix gives the base on the scale change from the quantity to rate. For the purpose, Matsui's equation: $W=Z L$ and the probability of processing, $P(0<P \leq 1)$ are here introduced.

Now, let us use the rate, $x$, by replace of $P$ as follows:

$P=X / Z=L / Z=x(0<x \leq 1)$, in which $X=m$. Then, the function, $y$, is defined by $y=\sqrt{x}$ in Figure A1!, and thus, the cross point is $y=x$.

Also, let us consider the functions of quantity, $Q$, as $Z(Q), L(Q)$ and $W(Q)$. When

$Q \rightarrow 0(Z \rightarrow \infty), \quad x=P=L / Z \rightarrow 0$ and $W \rightarrow 0$. Also, when $Q=Q(Z=L), \quad x-L / Z=1$.

Probably, if the function, $Z$, is derivative in $Q$ and monotone decreasing, then $Z^{\prime \prime}<0$. That is, $\sqrt{W}$ would be the concave function of $Q$ in Figure A2. By referring from Figure A1 to Figure A2, the basics of scale change to rate also hold in the rate of function on $Q$.

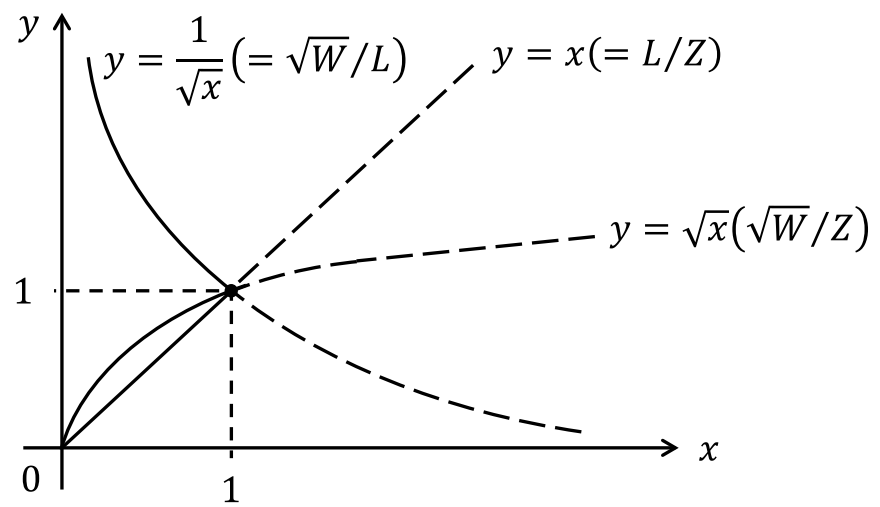

Figure A1. Scale change to rate.

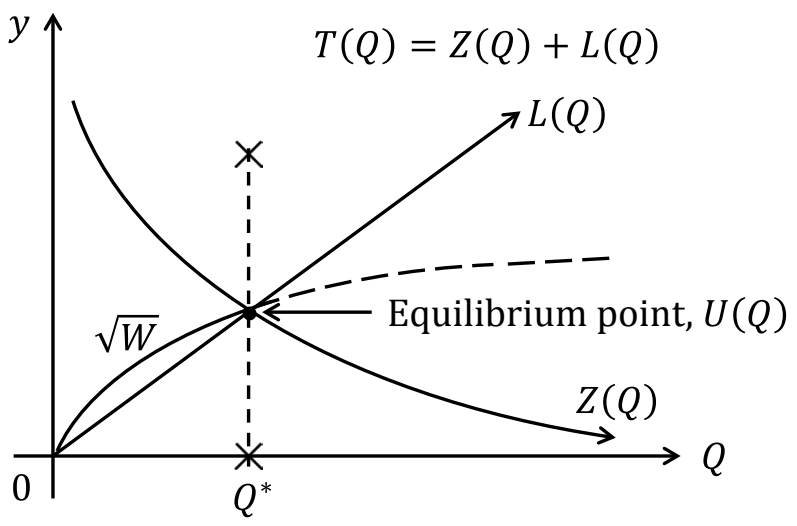

Figure A2. Function of quantity $(Q)$. 